\title{
Computer Vision Syndrome and Associated Factors Among Secretaries Working in Ministry Offices in Addis Ababa, Ethiopia
}

This article was published in the following Dove Press journal: Clinical Optometry

\author{
Mahlet Getachew Lemma' \\ Kidanemariam G/Michael \\ Beyene $^{2}$ \\ Mesafint Abeje Tiruneh (iD) ${ }^{3}$ \\ 'Training Department, Sun Optical \\ Technologies, Addis Ababa, Ethiopia; \\ ${ }^{2}$ Director General Office, Ethiopian Food \\ and Drug Authority, Addis Ababa, \\ Ethiopia; ${ }^{3}$ Medical Unit, Bethzatha \\ General Hospital, Addis Ababa, Ethiopia
}

Background: Prolonged use of computers led users to risk of computer vision syndrome (CVS). CVS is one of the occupational health problems. The aim of this study was to assess CVS and associated factors among secretaries working in government ministry offices in Addis Ababa, Ethiopia.

Materials and Methods: Institution-based cross-sectional study was conducted. Data were collected using interviewer administered pretested structured questionnaire and ophthalmic examinations. A total of 455 secretaries were participated in the study. Binary logistic regression analysis was applied to investigate determinants associated with CVS. Variables with p-value $<0.05$ were considered statistically significant.

Results: The prevalence of CVS among secretaries working in ministry offices in Addis Ababa was $68.8 \%$. The main reported symptoms were blurred vision (36.9\%), eye strain (32.1\%), redness of the eye $(27.3 \%)$ and headache $(26.4 \%)$. Average monthly income (AOR $=0.453,95 \% \mathrm{CI}$ : $0.235-0.874$ ), habit of frequent voluntary blinking ( $\mathrm{AOR}=0.313,95 \% \mathrm{CI}: 0.150-0.655)$, taking regular breaks between work ( $\mathrm{AOR}=0.279,95 \% \mathrm{CI}$ : 0.078-0.996), using computer eye/glasses/ spectacles $(\mathrm{AOR}=0.451,95 \% \mathrm{CI}: 0.245-0.830)$, sources of light at work place $(\mathrm{AOR}=0.009,95 \%$ CI: 0.001-0.076), using an antiglare filter $(\mathrm{AOR}=0.216,95 \% \mathrm{CI}: 0.117-0.401)$ and knowledge (AOR $=0.212,95 \%$ CI:0.115-0.389) were significantly associated with CVS.

Conclusion: Prevalence of CVS among secretaries was high. Average monthly income, habit of voluntary blinking, taking regular break, using computer spectacles, sources of light at work place, using an antiglare filter and knowledge were significantly associated with CVS. The findings suggest the need for adjusting exposure time to computers and increase awareness on safety measures and regular eye screening.

Keywords: computer vision syndrome; CVS, secretaries, ministry offices, Addis Ababa, Ethiopia

\section{Background}

Among office tools computers are common tools used and an integral part of professional day to day activities. Basic or advanced knowledge of computer technology facilitates complicated processes and functions. However, sitting continuously for long period with high vision demanding tasks in computers lead to develop computerrelated vision problems called computer vision syndrome (CVS). ${ }^{1,2}$

Continuous uses of computers for an extended hours cause physical afflictions such as vision abnormalities, headache, and low backache and might damage the mental health of individuals, including feelings of depression, anxiety and reluctantance to get 
up to go to work in the morning. ${ }^{2}$ The American Optometric Association defines CVS as:

a complex of eye and vision problems related to the activities which stress the near vision and which are experienced in relation to, or during, the use of the computers. It is characterized by visual symptoms which results from interaction with computer display or its environments. $^{3}$

The level of experiencing visual symptoms mainly depends on the individual's ability related to the visual demands of the activities performed. Studies found that most computer users face some vision symptoms., ${ }^{4,5}$ Globally, nearly sixty million people suffer from CVS and one million new cases occur every year. ${ }^{6}$ A national survey conducted in the United States showed that more than $14 \%$ of patients presented with vision-related symptoms which resulted from computer use. ${ }^{7}$

CVS is a common illness among individuals who use computers continuously that strain eyes. ${ }^{8}$ Many people face vision problems when they view a computer screen for long period of time. The common asthenopic symptoms related with CVS are blurred vision, double vision, eye fatigue, headaches, dry and irritated eyes, excessive tearing, red eyes, burning eyes, changing in color perception, light sensitivity, slowness in changing focus, and shoulder and neck pain. ${ }^{9-11}$ Many of the symptoms that cause CVS are preventable. Eliminating contributing factors is the most important interventions in management of CVS. $^{12}$

Due to the gaps in availability and utilization of personal protective equipment, workload, and poor knowledge of ergonomics during computer use, the burden of CVS is high in developing countries. Uncorrected vision conditions, contrast, poor lighting, glare, screen brightness, poor computer design, workplace ergonomics and highly demanding visual tasks are associated with visual symptoms and complaints. ${ }^{2,13,14}$ Poor seating posture, previous ocular illness, inappropriate viewing distances, systemic illness, age, poor resolution, source of lighting, poor contrast, unbalanced light between surroundings and computer screen, glare of the display and slow refresh rate are common factors that lead to CVS. ${ }^{15}$

CVS as a public health burden needs the attention of policymakers and researchers. The problem of CVS and risk factors are not well studied in Ethiopia. Hence, the study aimed to assess the magnitude of CVS and associated factors among secretaries working in government ministry offices in Addis Ababa, Ethiopia.

\section{Materials and Methods}

Study Design and Setting

Institution-based cross-sectional study was conducted among secretaries working in government ministry offices in Addis Ababa from October 28 to December 27, 2019. Addis Ababa is the capital city of Ethiopia and diplomatic center of the African Union. Addis Ababa has ten subcities and 116 districts. It has an estimated population of 3.2 million; among these $52.6 \%$ are females. During the study period, there were 19 government ministry offices in Addis Ababa. Based on the data collected from the Human Resource Department of the government ministries, there were a total of 731 secretaries in the 19 ministry offices.

\section{Study Population}

All secretaries who were working in the selected government ministry offices in Addis Ababa.

\section{Inclusion and Exclusion Criteria}

Secretaries who used computer to complete their day to day tasks for at least 2 hours per day for at least 12 months were included in the study. Whereas, secretaries with ocular disease such as: acute, chronic, infective conjunctivitis, any specific eyelid disorders, refractive error and other binocular vision problems which are not related with computer use were excluded.

\section{Sample Size Determination}

Single population proportion formula was used to determine sample size for prevalence of CVS and double population proportion formula for the associated factors assuming $73.9 \%$ proportion taken from previous study done in University of Gondar, Ethiopia, ${ }^{16}$ The total sample size was 489 with $95 \%$ confidence level, $5 \%$ marginal error, 1.5 design effect and 10\% non-response rate.

\section{Sampling Procedure}

To select the study participants from the government ministry offices, multistage sampling technique was used. There were 19 government ministry offices in Addis Ababa. Two stage sampling technique was used to select the study participants. First, 12 government ministry offices were randomly selected using lottery method. The number of secretaries in each ministry offices was collected from human resource department of each office. Then, the total sample size was proportionally allocated to the selected ministry offices proportional to the number of secretaries 
working in the ministry offices and simple random sampling technique was used to select the final study participants.

\section{Operational Definitions}

CVS: the presence of at least one of the symptoms of CVS such as eyestrain, eye fatigue, blurred vision, headache, dry eyes, red eyes, excessive tearing, blurred vision, double vision, sore/irritated eyes and changes in visualizing colors that occur related to computer use either intermittently or continuously for at least one week for the last 12 months. ${ }^{16,17}$

Appropriate seating position: The face of the secretary level to the computer screen and lines of sight to be depressed $20^{\circ}$ to $40^{\circ}$ from the horizontal eye level. ${ }^{18}$

Knowledge: Adequate knowledge means participants who scored greater than or equal to seven $(\geq 70 \%)$ questions out of 10 knowledge related questions and inadequate knowledge means participants who scored less than seven $(<70 \%)$ questions out of 10 knowledge related questions. ${ }^{16}$

Viewing distance: the distance between the computer screen and the user which measured in inches. The top of the screen should be below the horizontal eye level of the secretary with viewing distance of 20-28 inches. ${ }^{19}$

Glare on the display: the difference in brightness on the computer screen which comes because of facing unshaded windows. ${ }^{17}$

Using anti-glare reflection; filters which are placed over the computer screen to reduce glare and reflections. ${ }^{17}$

\section{Data Collection Procedures and Quality Assurance}

To fill the interviewer administered structured questionnaire, face-to-face interviews were carried out and ophthalmic examinations were done to collect data. The ophthalmic examinations of the participants were done to assess their visual acuity, ocular disease, eye health, refractive error and to investigate their prior exposure and spectacle use pattern. The examination was done while the study participants were in their actual work. Portable Slit lamp, biomicroscope, Ophthalmoscope, Radioscopy, Pinhole, Snellen visual acuity $\mathrm{E}$ chart and Metter tape were used to collect the data. In addition, to assess seating position appropriateness an observation with check list was used.

The questionnaire was prepared first in English and then translated to local language (Amharic) and then back translated to English in order to preserve the reliability of the tool. The interview questions were adapted from Recommended Components of an Eye/Vision Examination for Computer
Operators guideline developed by American Optometric Association $^{3}$ and modified to fit the study. The questionnaire consisted of questions related to socio-demographic factors, personal factors, environmental factors and knowledge about CVS. To assess the secretaries' knowledge about CVS, 10 questions in "True" or "False" forms were used and each question was coded and computed. Then scores were dichotomized into adequate knowledge (Participants who scored $\geq 70 \%$ on knowledge-based questions) and inadequate knowledge (Participants who scored $<70 \%$ on knowledge-based questions).

The questionnaire was pre-tested prior to data collection on $5 \%$ of secretaries working in ministry offices which were later not included in the study. Two trained optometrists collected the data under close supervision by the supervisor and principal investigator. The data collectors were oriented about the purpose of the study, data collection tools, ethical principles and what is expected from them prior to data collection. The principal investigator and supervisor checked out the collected data for completeness and accuracy.

\section{Data Management and Analysis}

The collected data were coded and entered into SPSS version 23 for analysis. Descriptive statistics were done to summarize the respondents' characteristics and presented using tables and graphs. Potential determinants with p-value $<0.25$ in bivariable binary logistic regression analysis analyses were included into the multivariable logistic model. The association between the dependent variable and independent variables was analyzed using binary logistic regression. To check the adequacy of the final model Hosmer-Lemeshow goodness of fit test was checked and the model fitted well to the data $(\mathrm{p}$-value $=0.306)$ and multi-collinearity was checked using variance inflation factor and there was no multi-collinearity. Variables were considered as statistically significant when $\mathrm{p}$-value $<0.05$.

\section{Results}

\section{Socio-Demographic Characteristics of Respondents}

Among the 489 secretaries, 455 participated in the study and the response rate was $93 \%$. The majority of the study participants, $172(37.8 \%)$ were in the age group of 30-39 years and the mean age of the respondents was $34.91(\mathrm{SD} \pm 8.74)$ years. Most of the study participants, 440 (96.7\%) were females and about half $(46.8 \%)$ of them were married. One-hundred ninety-eight (43.5\%) of the respondents had completed degree 
and above and nearly half of the secretaries had average monthly income of more than 3,000 Ethiopian Birr (Table 1).

\section{Personal Characteristics}

The viewing distance of $320(70.3 \%)$ of the respondents were less than $20 \mathrm{~cm}$ and the seating position of more than half $(53.6 \%)$ of them were inappropriate. Two-hundred eighty-four $(62.4 \%)$ of the secretaries worked in their current position for less than seven years and $366(80.4 \%)$ used computers for more than eight hours per day. One-hundred eighty-five (40.7\%) of respondents put the top of the computer screen aligned to eye level and $44(9.7 \%)$ of the participants had previous history of eye illness.

One hundred ninety-three (42.0\%) participants took regular breaks for less than 20 minutes and $301(66.2 \%)$ of them did not wear eye glasses/spectacle, and 439 $(81.9 \%)$ of the participants does not have the habit of voluntary blinking (Table 2).

\section{Computer and Environmental \\ Characteristics}

Majority of respondents, (79.3\%) used natural light as a source of lightning in their office. More than half of

Table I Socio-Demographic Characteristics of Study Secretaries Working in Ministry Offices, Addis Ababa, $2019(n=455)$

\begin{tabular}{|l|l|l|}
\hline Variables & Frequency (n) & Percent (\%) \\
\hline Gender & & \\
Male & 15 & 3.3 \\
Female & 440 & 96.7 \\
\hline Age (in years) & & \\
21-29 & 150 & 33 \\
$30-39$ & 172 & 37.8 \\
$>39$ & 133 & 29.2 \\
\hline Educational status & & \\
Certificate & 87 & 19.1 \\
Diploma & 170 & 37.4 \\
Degree and above & 198 & 43.5 \\
\hline Marital status & & \\
Single & 188 & 41.3 \\
Married & 213 & 46.8 \\
Divorced & 37 & 8.1 \\
Widowed & 17 & 3.7 \\
\hline Average monthly income & & 22.2 \\
I,500-2,500 ETB & 101 & 48.4 \\
$2,50 I-3,000$ ETB & 134 & \\
$>3,000$ ETB & 220 & \\
\hline
\end{tabular}

Table 2 Personal Characteristics of Secretaries Working in Ministry Offices, Addis Ababa, $2019(n=455)$

\begin{tabular}{|c|c|c|}
\hline Variables & $\begin{array}{l}\text { Frequency } \\
\text { (n) }\end{array}$ & $\begin{array}{l}\text { Percent } \\
(\%)\end{array}$ \\
\hline \multicolumn{3}{|l|}{ Seating position } \\
\hline Appropriate & 211 & 46.4 \\
\hline Inappropriate & 244 & 53.6 \\
\hline \multicolumn{3}{|l|}{ Viewing distance } \\
\hline$\leq 20 \mathrm{~cm}$ & 320 & 70.3 \\
\hline$>20 \mathrm{~cm}$ & 135 & 29.7 \\
\hline \multicolumn{3}{|l|}{ Level of top of computer } \\
\hline Above the eye level & 124 & 27.3 \\
\hline At the eye level & 185 & 40.7 \\
\hline Below the eye level & 146 & 32.1 \\
\hline \multicolumn{3}{|l|}{ Working hours with computer } \\
\hline$<8$ hrs. & 257 & 56.5 \\
\hline$\geq 8 \mathrm{hrs}$ & 198 & 43.5 \\
\hline \multicolumn{3}{|l|}{$\begin{array}{l}\text { Working years in the current } \\
\text { position }\end{array}$} \\
\hline$\leq 7$ years & 284 & 62.4 \\
\hline$>7$ years & $17 \mid$ & 37.6 \\
\hline \multicolumn{3}{|l|}{ Eye glasses/spectacle use } \\
\hline Yes & 154 & 33.8 \\
\hline No & 301 & 66.2 \\
\hline \multicolumn{3}{|l|}{ Eye glasses/spectacle purpose } \\
\hline Computer & 82 & 18 \\
\hline Other* & 72 & 15.8 \\
\hline \multicolumn{3}{|l|}{ Habit of voluntary blinking } \\
\hline Yes & 50 & 10.2 \\
\hline No & 439 & 81.9 \\
\hline \multicolumn{3}{|l|}{ Previous history of eye illness } \\
\hline Yes & 44 & 9.7 \\
\hline No & $4 I I$ & 90.3 \\
\hline \multicolumn{3}{|l|}{ Taking regular break } \\
\hline Yes & 193 & 42.4 \\
\hline No & 262 & 57.6 \\
\hline \multicolumn{3}{|l|}{ Length of break } \\
\hline$<20$ minute & 191 & 42.0 \\
\hline$\geq 20$ minute & 13 & 2.9 \\
\hline \multicolumn{3}{|l|}{ Systemic disease } \\
\hline Yes & 36 & 7.9 \\
\hline No & 419 & 92.1 \\
\hline
\end{tabular}

Note: * Eye glasses/spectacles for sunlight, cosmetics, covering ocular defect.

respondents claimed that there was a glare in their computer screen and only 160 (35.2\%) of them used antiglare filter. In addition, $256(56.3 \%)$ respondents adjusted their computer brightness (Table 3 ). 
Table 3 Computer and Environmental Characteristics of Secretaries Working in Ministry Offices, Addis Ababa, 2019 $(n=455)$

\begin{tabular}{|l|l|l|}
\hline Variable & Frequency (n) & Percent (\%) \\
\hline $\begin{array}{l}\text { Glare on the computer } \\
\text { Yes }\end{array}$ & 245 & \\
No & 210 & 53.8 \\
& & 46.2 \\
\hline $\begin{array}{l}\text { Use of antiglare screen } \\
\text { Yes }\end{array}$ & 160 & \\
No & 295 & 35.2 \\
\hline Source of lightning in office & & 64.8 \\
Natural light & 361 & \\
Fluorescent light & 94 & 79.3 \\
\hline Adjust computer brightness & & 20.7 \\
Yes & 256 & \\
No & 199 & 56.3 \\
\hline
\end{tabular}

\section{Knowledge About Computer Vision Syndrome}

From the total study participants, 266 (58.5\%) of the secretaries had adequate knowledge about CVS and 189 $(41.5 \%)$ of them had inadequate knowledge (Table 4$)$.

\section{Prevalence of Computer Vision Syndrome}

From the total secretaries participated in the study, 313 $(68.8 \%)$ of them had CVS. The most common symptoms reported were blurred vision (36.9\%), eye strain (32.1\%), redness of the eye $(27.3 \%)$ and headache $(26.4 \%)$ (Figure 1).

\section{Factors Associated with Computer Vision Syndrome}

In bivariate analysis ( $\mathrm{P}$-value $<0.25$ ), age, average monthly income, seating position, viewing distance, level of top of computer, using computer eye glass, habit of voluntary blinking, history of previous eye illness, taking regular break, length of break, source of lightning in the work place, adjusting computer brightness, glare on the computer, using antiglare filter and knowledge were significantly associated with CVS. However, in multivariable binary logistic regression analysis only average monthly income, habit of voluntary blinking, taking regular break, using eye glasses/spectacles, sources of light at work place, using an antiglare screen and knowledge were significantly associated with CVS.
Table 4 Knowledge About Computer Vision Syndrome (CVS) of Secretaries Working in Ministry Offices, Addis Ababa, 2019 $(n=455)$

\begin{tabular}{|l|l|l|}
\hline \multirow{2}{*}{ Knowledge Related Questions } & \multicolumn{2}{|l|}{ Response } \\
\cline { 2 - 4 } & True, $\mathbf{n}(\%)$ & False, $\mathbf{n}$ (\%) \\
\hline $\begin{array}{l}\text { There is eye problem caused by computer } \\
\text { use. }\end{array}$ & $268(58.9)$ & $187(41.1)$ \\
\hline $\begin{array}{l}\text { Lights that come out of computers affect the } \\
\text { eye. }\end{array}$ & $384(84.4)$ & $71(15.6)$ \\
\hline $\begin{array}{l}\text { Adjusting the brightness and contrast of } \\
\text { a computer is useful. }\end{array}$ & $317(69.7)$ & $138(30.3)$ \\
\hline $\begin{array}{l}\text { There is a material which can decrease glare } \\
\text { from the computer. }\end{array}$ & $322(70.8)$ & $133(29.2)$ \\
\hline $\begin{array}{l}\text { Seating position while using computer can } \\
\text { affect the eye. }\end{array}$ & $286(62.9)$ & $169(37.1)$ \\
\hline $\begin{array}{l}\text { Adjusting the appropriate distance from the } \\
\text { computer is useful. }\end{array}$ & $305(67)$ & $150(33)$ \\
\hline $\begin{array}{l}\text { There are eye glasses made to protect our } \\
\text { eyes from computer light. }\end{array}$ & $252(55.4)$ & $203(44.6)$ \\
\hline $\begin{array}{l}\text { One has to take a break in between of } \\
\text { a computer use. }\end{array}$ & $403(88.6)$ & $52(11.4)$ \\
\hline $\begin{array}{l}\text { Computer-related eye problem cannot be } \\
\text { solved medically. }\end{array}$ & $413(90.8)$ & $42(9.2)$ \\
\hline $\begin{array}{l}\text { Computer is made not to harm human eye at } \\
\text { all. }\end{array}$ & $315(69.2)$ & $140(30.8)$ \\
\hline
\end{tabular}

Those secretaries who had an average monthly income of greater than 3,000 Ethiopian Birr were 54.7\% less likely to develop CVS compared to those who had an average monthly income of 2,501-3,000 Ethiopian Birr (AOR $=0.453,95 \% \mathrm{CI}$ : $0.235-0.874)$.

Secretaries who used computer eye glasses/spectacles were $54.9 \%$ less likely to develop CVS compared to those who did not use eye glasses/spectacles $(\mathrm{AOR}=0.451,95 \%$ CI: $0.245-0.830$ ) and secretaries who had habit of voluntary blinking were $68.7 \%$ less likely to develop CVS compared to those who did not have the habit of voluntary blinking (AOR $=0.313,95 \%$ CI: $0.150-0.655$ ).

Secretaries who took regular breaks in between work were $72.1 \%$ less likely to develop CVS compared to those who did not take regular breaks $(\mathrm{AOR}=0.279,95 \% \mathrm{CI}$ : 0.078-0.996).

Secretaries who had a natural light source at their work place were $99.1 \%$ less likely to develop CVS compared to those who used fluorescent bulb as a source of light (AOR $=0.009$, 95\% CI: 0.001-0.076). 


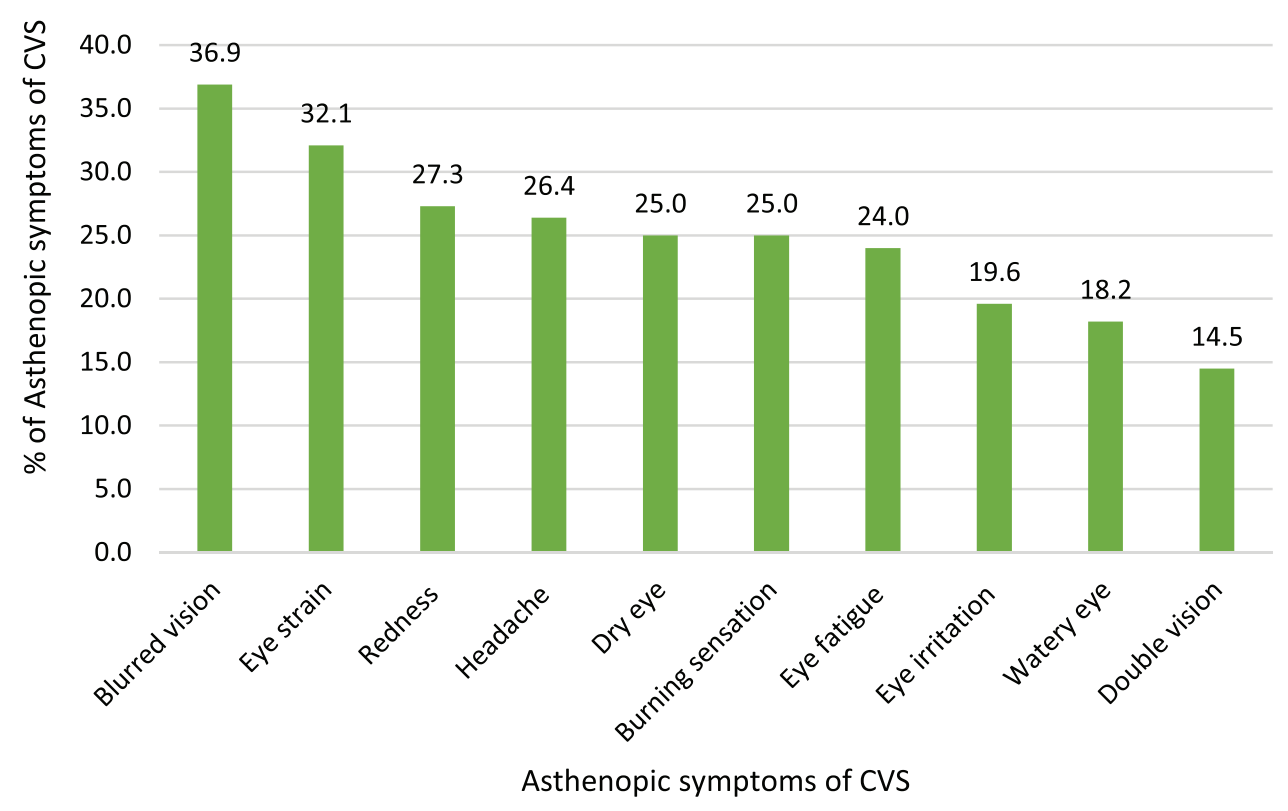

Figure I Asthenopic symptoms of computer vision syndrome (CVS) reported by secretaries working in Ministry Offices, Addis Ababa, 20I9 ( $\mathrm{n}=455$ ).

Secretaries who used antiglare filter were $78.4 \%$ less likely to develop CVS compared to those who did not use an antiglare filter (AOR $=0.216,95 \%$ CI: $0.117-0.401$ ).

Moreover, knowledge of secretaries on safety measures of computer use and its drawbacks was significantly associated with CVS. Secretaries who had adequate knowledge on the safe use of computers and its adverse effects were 78.3\% less likely to develop CVS compared to those who had inadequate knowledge ( $\mathrm{AOR}=0.212,95 \% \mathrm{CI}$ : $0.115-$ 0.389) (Table 5).

\section{Discussions}

The present study assessed magnitude of CVS and associated factors among secretaries working in Ministry Offices in Addis Ababa, Ethiopia. The study found out that the prevalence of CVS among the study participants were $68.8 \%$. The finding was almost comparable to studies conducted in Sri Lanka, Malaysia, United Arab Emirates, Pakistan and Debre Tabor (Northwest of Ethiopia ${ }^{20-24}$ and lower than reports in studies conducted in Chennai, India, Malaysia and Nigeria. ${ }^{8,17,24,25}$ The possible justification for this difference may be due to variations in study methods, study settings, data collection tools, study population and awareness on the safe use of computers.

In our study, the most commonly complained symptoms were blurred vision, eye strain, redness of the eye and headache. Previous studies conducted in India, Pakistan, Brazil and Nigeria ${ }^{17,21,25,26}$ showed that computer users are at high risk of visual symptoms. In addition, studies conducted in Debre Tabor and Gondar, Northwest Ethiopia had reported similar findings ${ }^{22}$ though study done in Ajman, United Arab Emirates reported that burning sensation, headache, dry/sore/ tired eyes were the most reported symptoms.

This study indicated that average monthly income was significantly associated with CVS. This finding is comparable to a study conducted in Debre Tabor, Northwest Ethiopia. ${ }^{22}$ Secretaries who had an average monthly income of greater than 3,000 ETB were 54.7\% less likely to develop CVS compared to those who had an average monthly income of 1,500-2,500 ETB. The possible reasons might be due to the fact executive secretaries had better salary as compared to other secretaries and might had reduced load of computer work as they usually have assistant secretaries working under them. In addition, high-paid secretaries might have better health care services access which could improve their visual symptoms and it might also be because they have better opportunity to use antiglare screen which can reduce development of CVS.

Using computer eye glasses/spectacles was significantly associated with CVS. This result was in line with a study done in Sri Lanka. ${ }^{23}$ Those secretaries who used computer eye glasses/spectacles were $54.9 \%$ less likely to develop CVS than those who did not use eye glasses/ spectacles. This might be because computer eye glasses/ spectacles are made up of coatings that can protect the eyes from harm full blue lights emitted from computer 
Table 5 Bivariate and Multivariable Logistic Regression Analysis on Factors Associated with Computer Vision Syndrome (CVS) Among Secretaries Working in Ministry Offices, Addis Ababa, $2019(n=455)$

\begin{tabular}{|c|c|c|c|c|c|}
\hline \multirow[t]{2}{*}{ Variables } & \multicolumn{2}{|c|}{ CVS } & \multirow[t]{2}{*}{ COR $(95 \% \mathrm{Cl})$} & \multirow[t]{2}{*}{ AOR $(95 \% \mathrm{Cl})$} & \multirow[t]{2}{*}{$P$ value } \\
\hline & Yes & No & & & \\
\hline \multicolumn{6}{|l|}{ Age (in years) } \\
\hline $21-29$ & 94 & 56 & I & 1 & \\
\hline $30-39$ & 116 & 56 & $1.234(0.779,1.954)$ & $0.836(0.437-1.600)$ & 0.589 \\
\hline$>39$ & 103 & 30 & $2.045(1.211,3.455)$ & $0.787(0.35 \mathrm{I}-1.767)$ & 0.562 \\
\hline \multicolumn{6}{|l|}{ Average monthly income } \\
\hline I,500-2,500 ETB & 70 & 31 & $0.790(0.470-1.327)$ & $0.588(0.285-1.090)$ & 0.088 \\
\hline $2,50 \mathrm{I}-3,000 \mathrm{ETB}$ & 80 & 54 & I & 1 & \\
\hline$>3,000 \mathrm{ETB}$ & 163 & 57 & $0.518(0.328-0.819)$ & $0.453(0.235-0.874)$ & $0.018 *$ \\
\hline \multicolumn{6}{|l|}{ Seating position } \\
\hline Appropriate & 121 & 90 & I & I & \\
\hline Inappropriate & 192 & 52 & $2.746(1.822,4.139)$ & 1.011 (0.448-2.28I) & 0.978 \\
\hline \multicolumn{6}{|l|}{ Viewing distance } \\
\hline$<20 \mathrm{~cm}$ & 226 & 94 & 1 & I & \\
\hline$\geq 20 \mathrm{~cm}$ & 87 & 48 & $0.754(0.492,1.155)$ & 1.005 (0.563-1.795) & 0.987 \\
\hline \multicolumn{6}{|l|}{ Level of top of computer } \\
\hline Above the eye level & 100 & 24 & I & 1 & \\
\hline At the eye level & 96 & 89 & $0.259(0.152,0.440)$ & $0.524(0.218-1.262)$ & 0.149 \\
\hline Below the eye level & 117 & 29 & $0.968(0.530,1.770)$ & $0.738(0.332-1.644)$ & 0.458 \\
\hline \multicolumn{6}{|l|}{ Computer Eye glasses/spectacle use } \\
\hline Yes & 76 & 237 & $0.263(0.173,0.400)$ & $0.451(0.245-0.830)$ & $0.011 *$ \\
\hline No & 78 & 64 & I & I & \\
\hline \multicolumn{6}{|l|}{ Habit of voluntary blinking } \\
\hline Yes & 31 & 51 & $0.197(0.119-0.326)$ & $0.313(0.150-0.655)$ & $0.002^{*}$ \\
\hline No & 282 & 91 & 1 & 1 & \\
\hline \multicolumn{6}{|l|}{ Previous history of eye disease } \\
\hline Yes & 36 & 8 & $2.177(0.985-4.813)$ & $2.566(0.964-6.835)$ & 0.059 \\
\hline No & 134 & 134 & I & I & \\
\hline \multicolumn{6}{|l|}{ Taking regular break } \\
\hline Yes & 111 & 82 & $0.402(0.268,0.603)$ & $0.279(0.078-0.996)$ & $0.049 *$ \\
\hline No & 202 & 60 & I & 1 & \\
\hline \multicolumn{6}{|l|}{ Length of break } \\
\hline$\leq 20$ minute & 110 & 81 & $0.417(0.277-0.628)$ & $2.227(0.618-8.037)$ & 0.221 \\
\hline$>20$ minute & 11 & 2 & 1 & I & \\
\hline \multicolumn{6}{|l|}{ Source of light at working place } \\
\hline Natural light & 220 & $|4|$ & $0.017(0.002-0.122)$ & $0.009(0.00 \mathrm{I}-0.076)$ & $<0.00 I^{*}$ \\
\hline Fluorescent bulb & 93 & 1 & 1 & 1 & \\
\hline \multicolumn{6}{|l|}{ Adjusting contrast and brightness } \\
\hline Yes & 166 & 90 & $0.652(0.434,0.980)$ & $1.701(0.915-3.161)$ & 0.093 \\
\hline No & 147 & 52 & I & 1 & \\
\hline \multicolumn{6}{|l|}{ Glare on the display } \\
\hline Yes & 175 & 70 & $1.304(0.877,1.941)$ & $0.836(0.463-1.5 \mathrm{I})$ & 0.553 \\
\hline No & 138 & 72 & I & 1 & \\
\hline
\end{tabular}

(Continued) 
Table 5 (Continued).

\begin{tabular}{|l|l|l|l|l|l|}
\hline \multirow{2}{*}{ Variables } & \multicolumn{2}{l|}{ CVS } & \multicolumn{2}{l|}{ COR (95\% CI) } & AOR (95\% CI) \\
\cline { 2 - 5 } & Yes & No & & Palue \\
\hline $\begin{array}{l}\text { Using of anti-glare filter } \\
\text { Yes }\end{array}$ & 73 & 87 & $0.192(0.125-0.295)$ & $0.216(0.117-0.401)$ \\
No & 240 & 55 & 1 & 1 & $<0.001 *$ \\
\hline $\begin{array}{l}\text { Knowledge } \\
\text { Adequate } \\
\text { Inadequate }\end{array}$ & 148 & 118 & $0.182(0.112-0.298)$ & $0.212(0.115-0.389)$ \\
\hline
\end{tabular}

Note: *statistically significant associations at $\mathrm{p}$-value $<0.05$

Abbreviations: $\mathrm{AOR}$, adjusted odds ratio; $\mathrm{COR}$, crude odds ratio; $\mathrm{Cl}$, confidence interval.

screen and concurrently reduces asthenopic symptoms of CVS. Blue lights are the most dangerous of all lights. All computers and digital devices emit blue light and studies confirmed that cumulative life time exposure to blue light causes different eye illnesses. ${ }^{27}$

In our study, habit of voluntary blinking was significantly associated with CVS. Secretaries who had habit of voluntary blinking were $68.7 \%$ less likely to develop CVS than those who did not have the habit of voluntary blinking. The level of human's blink varies dramatically during computer use. At rest the average natural eye blink rate is $15-16$ blinks per minute. When there is high concentration and visual demand the rate drops to $5-6$ blinks per minute and it further goes down to 3-4 times a minute while working on computers. This fewer blink will lead to dryness of the eye due to less lubrication of the tear meniscus. ${ }^{28}$ Since significantly reduced blink rates and increased corneal exposure have been observed at the time of computer operations, CVS may be primarily caused by dry eye. ${ }^{29}$

In this study, taking regular break in between works was significantly associated with CVS. The finding is similar to previous studies done in India, Ajman United Arab Emirates, Pakistan, Debre Tabor and Gondar (Northwest Ethiopia. ${ }^{16,17,20-22}$ Secretaries who took regular break in between work were $72.1 \%$ less likely to develop CVS compared to those who did not take regular break. This might be due to the fact that taking regular task breaks during continuous computer work helps to reduce eye strain as changing eye focus from computer screen relaxes the eye muscles and accommodative system which increases the efficiency of work. ${ }^{20,30}$

Source of light in working place was statistically significant variable in our study. This result was supported by study done in India. ${ }^{17}$ Secretaries who used natural light as a source of light at their work place were $99.1 \%$ less likely to develop CVS than those who used fluorescent bulb. Studies showed that proper lighting, elimination of glare and using non-reflective coatings are essential factors for an optimal visual display design. High sensitivity and illumination to glare decrease the attention to the task and increase reading time. ${ }^{31}$

The study indicated that using antiglare filter was significantly associated with CVS. This result is similar to a study conducted in Ajman, United Arab Emirates. ${ }^{20}$ Those secretaries who used antiglare filter were $78.4 \%$ less likely to develop CVS than those who did not use. This might be due to anti-glare filters diminish glare and reflection from the computer screen and reduce asthenopic symptoms. ${ }^{32}$

The study showed that knowledge on safety measures of computer use and its drawbacks was significantly associated with CVS. The result was comparable to a study conducted in a Nigeria, Debre Tabor, Ethiopia, and Malaysia. ${ }^{22,24,33}$ Secretaries who had adequate knowledge on safe use of computers and its adverse effects were $78.3 \%$ less likely to develop CVS than those who had inadequate knowledge. The possible justification might be due to the fact that workers who have good knowledge might implement protective measures to reduce the possibility of developing CVS.

The most worrying issue in our study is that the level of CVS was high and this could create unusual strain on the eye. Unfortunately, the severity of the problem was not recognized and addressed sufficiently. As a result, CVS could significantly reduce the quality of life and impair workplace productivity by predisposing uncommon damage to the eye. The level of awareness and ergonomic practices at the work place is low. 


\section{Strength and Limitation of the Study}

The main strength of this study was that both ophthalmic examination and self-reports of the symptoms was done to measure CVS of the secretaries. There might be recall bias among secretaries due to the fact that they were expected to recall information from their past experiences.

\section{Conclusion}

A high proportion of secretaries working in ministry offices in Addis Ababa suffered from CVS. Average monthly income, habit of voluntary blinking, taking regular break, using computer eye glasses/spectacles, source of light at work place, using antiglare filter and knowledge were determinant factors to CVS. Blurred vision, eye strain, redness of the eye and headache were the most commonly experienced visual related problems. Hence, optimizing exposure time to computers, increasing awareness on safety measures and regular eye screening are essential to minimize CVS.

\section{Data Sharing Statement}

The data regarding this article are available in the manuscript.

\section{Ethics Approval and Consent to Participate}

As our institutions do not have the mandate to provide ethical clearance for research, ethical clearance was obtained from Addis Ababa Health Bureau and GAMBY Medical and Business College. This study was conducted under technical support and supervision of GAMBY Medical and Business College. The study was carried out in accordance with the Declaration of Helsinki. To assure autonomy written informed consent was obtained from the study participants. The study participants were informed that their responses will not have effect on their day to day activities and informed written consent was obtained. The study participants were assured about confidential information. Personal identifiers were omitted during data collection. The interview questionnaires and collected data were kept confidential throughout the research work and access restricted to the research team only.

\section{Consent for Publication}

Consent for publication was taken from the study participants.

\section{Acknowledgments}

The authors would like to thank GAMBY Medical and Business College, Addis Ababa Health Bureau, data collectors and study participants for their collaboration and contribution.

\section{Author Contributions}

All authors made a significant involvement and contribution to this article. The contribution includes conception, study design, execution, acquisition of data, analysis and interpretation. It also includes took part in drafting, revising or critically reviewing the article; gave final approval of the version to be published. All authors have agreed on the journal to which the article has been submitted; and to be accountable for all aspects of this article.

\section{Funding}

The authors received no funding for this work.

\section{Disclosure}

The authors declared that they have no competing interests.

\section{References}

1. MacKinnon G. A decade of laptop computers: the impact on the pedagogy of university faculty. $J$ Instruction Delivery Sys. 2007;21:7-20.

2. Anshel J. Visual Ergonomics Handbook in Computer Vision Syndrome. 1st ed. Boca Raton, FL, USA: CRC Press Taylor \&Fransis Group; 2005.

3. American Optometric Association. Guide to the Clinical Aspects of Computer Vision Syndrome. St. Louis, MO, USA; 1995.

4. Smith M, Cohen B, Stammer LW, Happ A. An investigation of health complaints and job stress in video display operations. Hum Factors. 1981;23(4):387-400. doi:10.1177/001872088102300402

5. National Institute for Occupational Safety and Health. Potential health hazards of video display terminals DHHS (NIOSH) publication No. 81-129. 1981.

6. Abdelaziz M, Fahim S, Mousa D, Gaya B. Effects of computer use on visual acuity and colour vision. Eur J Sci Res. 2009;35:99-105.

7. Sheedy J. Vision problems at video display terminals: A survey of optometrists. J Am Optometry Assoc. 9921;63(10):687-692.

8. Logaraj M, Madhupriya V, Hegde S. Computer vision syndrome and associated factors among medical and engineering students in Chennai. Annals of Medical and Health Sciences Research. 2014;4 (2):179-185. doi:10.4103/2141-9248.129028

9. Kozeis N. Impact of computer use on children's vision. Hippokratia. 2009;13(4):230-231.

10. Gangamma MP, Poonam P, Rajagopala M. A clinical study on "Computer vision syndrome" and its management with Triphala eye drops and Saptamrita Lauha. AYU (An International Quarterly Journal of Research in Ayurveda). 2010;31(2):236-239. doi:10.4103/0974-8520.72407

11. Sen A, Richardson S. A study of computer-related upper limb discomfort and computer vision syndrome. J Hum Ergol. 2007;36(2):45-50. 
12. Ranasinghe P, Wathurapatha W, Pereraetal YS. Computer vision syndrome among computer office workers in a developing country: an evaluation of prevalence and risk factors. BMC Res Notes. 2016;9 (1):150-158

13. Salibello C, Nilsen E. Is there a typical VDT patient? A demographic analysis. J Am Optometry Assoc. 1995;66(8):479-483.

14. Charpe N, Kaushik V. Computer vision syndrome (CVS): recognition and control in software professionals. J Human Ecology. 2009;28 (1):67-69. doi:10.1080/09709274.2009.11906219

15. Computer Vision TJ. Syndrome: understanding computer vision syndrome. Occupational Safety Health Admin. 2012;828(1):2-4.

16. Alemayehu M, Nega A, Tegegne E, Mule Y. Prevalence of self reported computer vision syndrome and associated factors among secretaries and data processors who are working in University of Gondar, Ethiopia. J Biol Agri Healthcare. 2014;4(15):33-37.

17. Bhanderi D, Choudhary S, Doshi V. A community-based study of asthenopia in computer operators. Indian J Ophthalmol. 2008;56 (1):51-55. doi:10.4103/0301-4738.37596

18. Singh H, Tigga M, Laad S, Khan N. Prevention of ocular morbidity among medical students by prevalence assessment of asthenopia and its risk factors. Journal of Evidence Based Medicine and Healthcare. 2016;3(15):532-536. doi:10.18410/jebmh/2016/122

19. Ripple P. Variation of accommodation in vertical directions of gaze. Am J Ophthalmol. 1952;35(11):1630-1634. doi:10.1016/00029394(52)91453-0

20. Shantakumari N, Eldeeb R, Sreedharan KG, Gopal K. Computer use and vision-related problems among university students in Ajman, United Arab Emirate. Ann Med Health Sci Res. 2014;4(2):258-263. doi:10.4103/2141-9248.129058

21. Noreen K, Batool Z, Fatima T. Prevalence of computer vision syndrome and its associated risk factors among under graduate medical students of Bahria University Medical and Dental, Karachi, Pakistan. Pakistan J Ophthalmol. 2016;32(3):140-146.

22. Awrajaw D, Fentahun A, Ansha A, Sintayehu D, Computer Vision HD. Syndrome and Associated Factors among Computer Users in Debre Tabor Town, Northwest Ethiopia. J Environ Public Health. 2018;25(3):140-146.
23. Ranasinghe P, Wathurapatha W, Perera Y, et al. Computer vision syndrome among computer office workers in a developing country: an evaluation of prevalence and risk factors. BMC Res Notes. 2016;9 (1):2-9. doi:10.1186/s13104-016-1962-1

24. Loh K, Redd S. Understanding and preventing computer vision syndrome. Malaysian Family Phys. 2008;3(3):128-130.

25. Akinbinu R. Knowledge of computer vision syndrome among computer users in the workplace in Abuja, Nigeria. Journal of Physiology and Pathophysiology. 2013;4(4):58-63. doi:10.5897/JPAP2013.0078

26. Endwardo S, Lys R. The prevalence of risk factors associated with Computer Vision Syndrome among computer works in São Paulo, Brazil. Occup Environ Med. 2014;71(1):A103.

27. Amy L, James S. Digital eye strain: prevalence, measurement and amelioration. BMJ Open Ophthalmology. 2018;3:1-10.

28. Yan Z, Hu L, Chen H, Lu F. Computer vision syndrome: a widely spreading but largely unknown epidemic among computer users. Computers Human Behav. 2008;24(5):2026-2042. doi:10.1016/j. chb.2007.09.004

29. Saman W. Computer vision syndrome. Galle Med J. 2006;11 (11):25-29.

30. Fenety A, Walker M. Short-Term Effects of Workstation Exercises on Musculoskeletal Discomfort and Postural Changes in Seated Video Display Unit Workers. Phys Ther. 2002;82(6):578-589. doi:10.1093/ $\mathrm{ptj} / 82.6 .578$

31. Occupational Health Clinic for Ontario Workers Inc. Office Ergonomics Handbook: Occupational Health Clinics for Ontario Workers. 5th ed. 2008.

32. Rosenfield M. Computer vision syndrome: a review of ocular causes and potential treatments. Ophthalmic Physiological Optics. 2011;31 (5):502-551. doi:10.1111/j.1475-1313.2011.00834.x

33. Stella C, Chiemeke M, Allen E, Akhahowa A, Olajire B Evaluation of Vision-Related Problems amongst Computer Users: A Case Study of University of Benin, Nigeria. WCE. Proceedings of the World Congress on Engineering 2007.
Clinical Optometry

\section{Publish your work in this journal}

Clinical Optometry is an international, peer-reviewed, open access journal publishing original research, basic science, clinical and epidemiological studies, reviews and evaluations on clinical optometry. All aspects of patient care are addressed within the journal as well as the practice of optometry including economic and business analyses. Basic and clinical research papers are published that cover

Submit your manuscript here: https://www.dovepress.com/clinical-optometry-journa

\section{Dovepress}

all aspects of optics, refraction and its application to the theory and practice of optometry. The manuscript management system is completely online and includes a very quick and fair peer-review system, which is all easy to use. Visit http://www.dovepress.com/ testimonials.php to read real quotes from published authors. 